\title{
Continental French, Corsican French, and the interpretation of intonation: The effect of implicit social cues depends on exposure
}

\author{
James S. German ${ }^{1}$, Cristel Portes ${ }^{1}$ \\ ${ }^{1}$ Aix-Marseille Université, CNRS, LPL, Aix-en-Provence, France \\ james.german@lpl-aix.fr, cristel.portes@lpl-aix.fr
}

\begin{abstract}
Recent studies have shown that the interpretation of intonational patterns can be influenced by social cues that relate those patterns to sociolectal variation [1,2]. [2] found that Corsican French listeners interpreted a penultimate risefall contour differently depending on which type of implicit social cue was present, reflecting the fact that the contour generally expresses questions in Corsican French and statements in Continental French. [2, 3, 4] suggest that the tendency for social cues to influence perception depends on the amount of exposure that a given sociolectal group has with another. Crucially, Continental French individuals generally have some exposure to Corsican French, though comparatively less than the other way around. This raises the question of whether Continental French listeners are similarly sensitive to social cues in the interpretation of the penultimate rise-fall. The present study tests this hypothesis using the same design as [2]. As expected, Continental French listeners are less likely to interpret the penultimate rise-fall contour as a question, though no significant effect of social cue type was found. This finding corroborates the important role that exposure plays in social priming effects. The combined findings are compared to the predictions of an exemplar theoretic model presented in [2].
\end{abstract}

Index Terms: social priming, dialect contact, intonation, exemplar theory, Corsican French

\section{Introduction}

Social priming in perception occurs when differences in contextual cues to social indices influence the perceptual behavior of listeners, such as when a difference in cues to gender [5], region [6, 7, 8], or age [9] cause a shift in the categorization boundary between neighboring phonemes or in the subjective perception of vowel quality. These effects can be found in cases of sociolectal contact, where a given population has experience with at least two different sociolectal patterns, each of which is associated with a readily identifiable social index. As an example, New Zealand English (NZE) speakers have substantial experience with Australian English (AusE), which differs from NZE in terms of the phonetic realization of vowel phonemes. As [8] showed, the presence of contextual cues to "Australia" in the laboratory caused listeners to perceive the quality of vowels as slightly more AusE-like as compared to when cues to "New Zealand" were present. While such effects are readily predicted and accounted for by exemplar theoretic models $[10,11]$, at least two recent studies call into question whether they generalize to all contexts involving contact between sociolectal groups. First, using a design similar to [6, 7], [3] tested whether regional labels to Northern England (Sheffield) versus southern England (London) would influence the subjective perception of vowel quality by Southern Standard British English (SSBE) listeners, and found no effect. Second, [4], using a design similar to [8], tested whether AusE listeners exhibit the same sensitivity to regional cues as NZE listeners, and also found no effect. The authors suggest that this result is surprising; since Australians are generally familiar with NZE, the social priming effect should be reciprocal.

The present study involves a similar test of the reciprocity of social priming between two sociolectal groups in contact, namely Corsican French and Continental French speakers. It builds on [2], which found that implicitly presented social cues to region (Corsica versus Paris) influenced how Corsican French listeners interpret a particular intonation contour as either a question or a statement. The intonational contour in question involves a final rise-fall whose peak is aligned to the penultimate syllable of the utterance. Both Corsican French and Continental French include such a contour in their inventory (Figure 1), though the two varieties differ in how it is used. In Corsican French, a penultimate rise-fall (henceforth PRF) is used primarily to mark polar questions [12], while in Continental French it is used to mark a specific type of statement which contrasts with the canonical declarative pattern involving a fall through the final prosodic constituent $[13,14,15,16]$. Since Corsicans have substantial experience with Continental French through media, travel, and tourism, the authors hypothesized that contextual cues to the different regions would influence how Corsican French listeners interpret the PRF. Participants were presented with tokens of the contour as produced by a Continental French speaker and were asked to choose between dialogue completions that were consistent with the target utterance being either a question or statement. In a between-subjects manipulation, one of two regional newspapers (Corsican or Parisian) was placed next to the participants during the task. As hypothesized, participants in the Corsican newspaper condition provided significantly more question-consistent responses as compared to those in the Parisian newspaper condition (Figure 2). The authors interpret the finding as support for the prediction of exemplartheoretic models that perception is guided by the activation of prior stored experiences which are linked to contextual information such as social indices.

[2] additionally provide an exemplar-theoretic model simulation of their participants which predicts how the social priming effect should depend on individuals' prior experience with the two varieties, and more specifically, on the relative proportion of input they have encountered from the two varieties. The simulation suggests that Corsican French individuals, who typically have a more balanced experience with the two varieties, are expected to be influenced by the social primes more robustly than Continental French individuals, who while familiar with Corsican French largely 
through social stereotyping [17], have a quantitatively much more limited exposure to that variety.

The present study tests this prediction through an experiment involving the same design and materials as [2] but with Continental French listeners. We hypothesize, first of all, that Continental French listeners will be less likely to interpret the PRF as a question, and more importantly, that their tendency to do so will be less sensitive to the social prime manipulation as compared with Corsican French listeners.
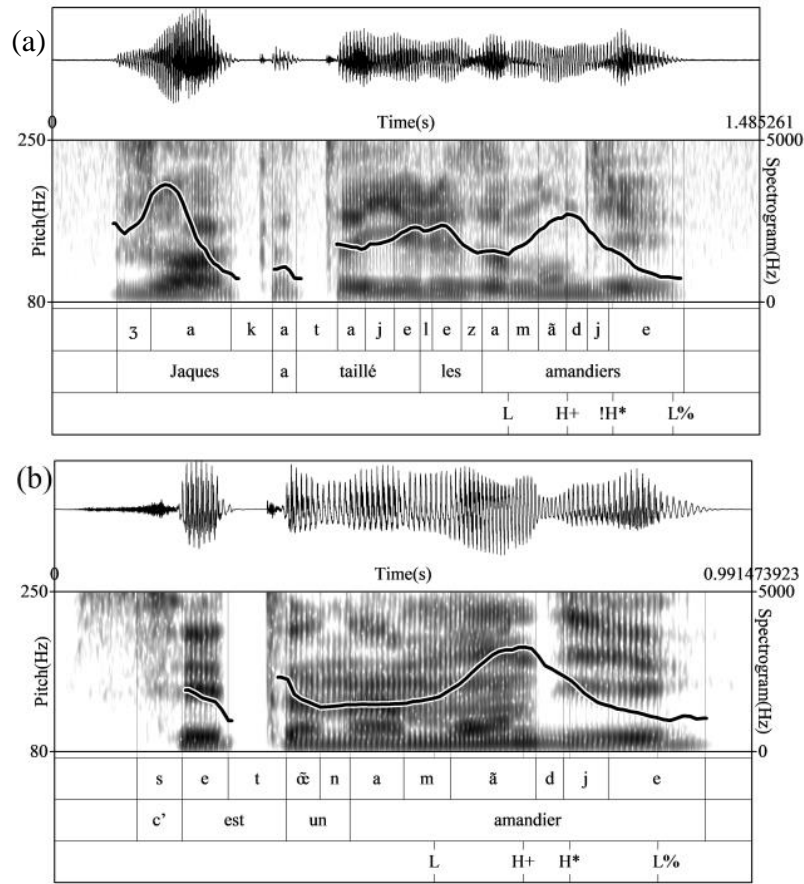

Figure 1: Penultimate rise-fall contours (PRFs) as produced by a Corsican French speaker (a) and by the Continental French speaker used in the present study (b).

\section{Methods}

\subsection{Participants}

48 individuals participated in the study as unpaid volunteers. All were native speakers of continental French and resided in continental France at the time of the study. Three participants self-reported reading or other language disorders and were excluded. One participant reported having spent a substantial amount of time in Corsica and was therefore excluded. The resulting 44 participants consisted of 18 men, 25 women, and one non-binary person, with a mean age of $19.8(\mathrm{SD}=2.8)$.

\subsection{Materials}

The materials, including targets, contexts, fillers, and response options are identical to those used in [2], and are reported there in detail. The experimental targets consisted of 32 utterances involving declarative syntax (ex. 2) and a penultimate rise-fall contour (Figure 1b). All were produced by a male native speaker of Continental French. Each target was paired with two types of preceding contexts. These contexts involved short descriptions of situations involving a recurring character named Antoine, who is understood to be the speaker of the target utterances. One type of context was designed to set up an expectation that the target utterance is a question, while the other is intended to be neutral in this regard. This step was taken in order to establish that participants' response choices indeed reflect their illocutionary interpretation of the target sentences; it was accomplished by varying the verb of reported speech in the final sentence of the context (e.g... Il lui demande... 'He asks her...' as in (1a) versus Il s'adresse à elle... 'He speaks to her...' as in (1b)). The pair of contexts associated with each target sentence were identical in all other respects. Each target sentence was also paired with two response options which represent different ways that Antoine's interlocutor could continue the dialog. One of these options was designed to be consistent with an interpretation of the target utterance as a question (3a), while the other was designed to be consistent with interpreting it as a statement (3b).

(1) a. Question-biasing context:

Antoine cuisine avec sa mère. Il lui demande...

'Antoine is cooking with his mother. He asks her...'

b. Neutral context:

Antoine cuisine avec sa mère. Il s'adresse à elle...

'Antoine is cooking with his mother. He speaks to her...'

(2) Target sentence :

Il faut mélanger.

'Should I stir?' (question)

'You have to stir.' (statement)

(3) a. Question-consistent response:

Je crois que oui. 'I think so.'

b. Statement-consistent response.

D'accord. 'Okay.'

60 filler items were included as distractors. These also involved declarative syntax but were produced with either a final rising intonation (30 items), or with a contour involving a fall through the final accentual phrase (30 items). Four lists were created each involving 32 experimental items and 60 fillers. In each list, 24 of the experimental items appeared with a Neutral context, and 8 appeared with a Question-biased context. The attribution of items to context condition was counterbalanced across the lists. Experimental items and fillers were assigned to 8 balanced blocks, and block order was randomized for each participant. Additionally, each list occurred in two versions according to the left-right orientation of the response options associated with experimental items.

Two regional daily newspapers were used as visual social primes in the experiment: Corse Matin (CORSICAN condition) and Le Parisien (CONTINENTAL condition) These are the same newspapers that were used in [2]; they are similar to each other in size and layout, and were selected to include as much region-specific information as possible.

\subsection{Procedures}

Participants were seated at a desk with a laptop and soundinsulating headphones. Before they entered the room, one of 
the two newspapers described in 2.2 was placed next to the laptop. Once participants were seated, the experimenter drew attention to the newspaper by asking if it belonged to the participant and then dismissed it as perhaps belonging to a previous participant. Participants were then asked to read the instructions, and the experimenter stepped out of the room for several minutes in order to give ample time for participants to observe the newspaper before the experiment. 23 participants were assigned to the CONTINENTAL condition and 21 to the CORSICAN condition.

Presentation of the items was controlled using E-Prime 2.0.10.353 (Psychology Software Tools, Pittsburgh, PA) and was self-paced. For each item, the (textual) context first appeared on the screen. After reading the context, participants pressed the spacebar to hear the audio of the target, and then again to hear it a second time. After the second playback, the response options appeared below the context, and participants were asked to choose the option that was the most appropriate reaction to the target by 'Antoine's' interlocutor. No time limit on responses was enforced.

\section{Results}

A total of 1408 experimental trials were collected. As in [2], items were removed which fell outside of two standard deviations of the mean of the logarithm of response time, resulting in 1339 trials used for analysis.

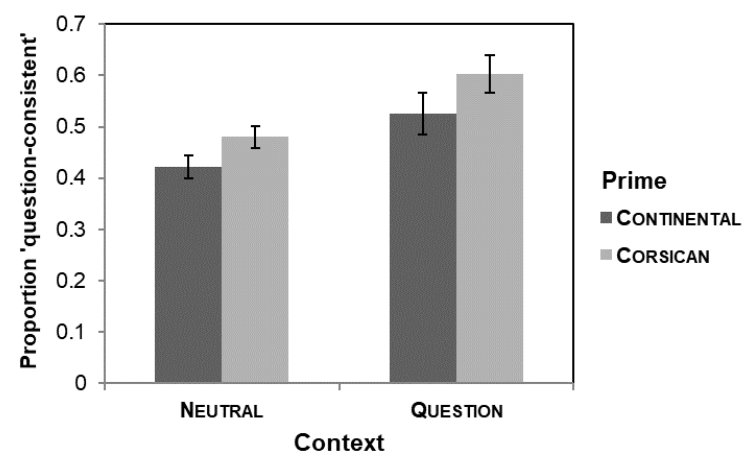

Figure 2: Proportion of question-consistent responses by Context and Prime for Corsican French listeners. (As reported in [2].)

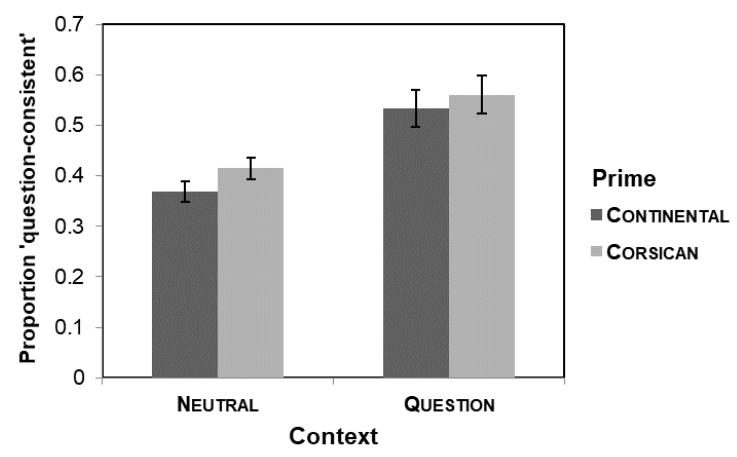

Figure 3: Proportion of question-consistent responses by Context and Prime for Continental French listeners in the present study.
A summary of the results is shown in Figure 3. As expected, participants responded with a question-consistent response more often in the QUESTION-BIASED context than in the NeUTRAL context. Descriptively, participants provided a question-consistent response more often in the CORSICAN prime condition than in the CONTINENTAL prime condition. To assess these differences statistically, a generalized logistic mixed model was fit to the data using the glmer function (lme4 package, [18]) in $\mathrm{R}$ [19] with a logit link, and response type (question-consistent, statement-consistent) as the binary dependent variable. Prime, Context, and their interaction were included as fixed factors, while the maximal random effect structure that converged included random intercepts for participants and items and random slopes for participants by context. To assess which factors significantly contributed to the fit of the model, model comparisons by likelihood ratio tests were carried out by stepwise removal. As in [2], there was a significant main effect of context $(\chi 2=14.0, p<0.001)$, though unlike [2], the main effect of social prime type was not significant $\left(\chi^{2}=0.928, p=0.335\right)$. No significant interaction between these two factors was found $(\chi 2=0.16, p=0.69)$.

As hypothesized, Continental French listeners interpreted the PRF less often as a question than did Corsican French listeners $(42.9 \%$ vs. $48.2 \%)$. Since the study in [2] and the present study were carried out in different locations under slightly different conditions, they technically represent distinct experiments. We nevertheless carried out a post hoc statistical analysis of the combined results to explore (a) the descriptive finding above that the two populations interpret the PRF differently, and (b) whether there was a significant interaction between participant group (Corsican versus Continental) and Prime, since the latter would lend further support to the hypothesis that the two populations differ in their sensitivity to the social primes. This combined test had the structure of the one described above with the addition of participant group (Corsican French versus Continental French) as a fixed factor, and the addition of random slopes for items by context. The effect of participant group was found to be significant $\left(\chi^{2}=\right.$ $6.82, p<0.01)$. There was, however, no significant interaction between participant group and Prime $(\chi 2=0.33, p=0.57)$.

\section{Discussion}

Overall, the results of the present study support our two main hypotheses. First, the fact that Continental French listeners tend to interpret the PRF less often as a question as compared to Corsican French listeners corroborates previous descriptions of the two varieties which suggest that the PRF is used primarily as a question by Corsican French speakers and as a statement by Continental French speakers. Second, the fact that the social prime manipulation did not significantly influence the interpretation of the PRF by Continental French listeners is consistent with our prediction based on the observation that those individuals have comparatively less exposure to Corsican French. Ideally, the study in [2] and the present study would have been conducted as a single experiment. The fact that there was no significant interaction between participant group and prime in the combined test supports the importance of doing so in future research.

[4] suggest that the lack of an effect of social prime among AusE listeners is surprising, based on the fact that Australians generally have a high familiarity with NZE. Nevertheless, the authors also provide as a possible explanation for this lack of effect that "the [Australian] participants may not have the 
level of NZE exposure required...", and that in fact "20 of the 75 participants...had never been to New Zealand, didn't speak with, or know, any New Zealanders, and couldn't name any New Zealand media" (p. 21). The distinction between familiarity and exposure is crucial given the mechanism by which exemplar-based models predict social priming effects. In category selection for example, exemplars are activated, first of all, according to their degree of phonetic similarity with the input. Each category (e.g., a phoneme or wordform) is in turn activated as a function of the summed activation of all exemplars which are indexed to it, and the category with the highest overall summed activation is selected. Social priming influences this process by raising the baseline activation of all exemplars which are associated to the relevant social index [10]. This causes the system to behave slightly more as though it were composed only of exemplars associated to that social index. In other words, a NZE speaker exposed to a cue to Australia will behave slightly more like an individual who has only been exposed to AusE, and the boundary between two neighboring vowel categories will shift gradiently in the direction of the AusE pattern. Crucially, however, the set of exemplars favored by activation of the social index are in competition with all other exemplars that are also phonetically similar to the input. Since the activation of a category is the sum of activation of its associated exemplars, then if exemplars not associated to the activated social index greatly outnumber those that are so associated, the overall contribution of socially indexed exemplars will be small. In short, the strength of the social priming effect is predicted to depend on the size of the set of exemplars associated to a given social index relative to the total set of exemplars in the individual's experience. This aspect of exemplar-theoretic models therefore correctly predicts that social priming effects should be large (and therefore readily detectable) when a population has relatively balanced exposure to two sociolects, as in $[1,2,5,6,7,9,10]$, and small (and therefore absent or at least difficult to detect) when a population has only limited exposure to one of the two sociolects in question, as in $[3,4]$ and the present study.

[2] provide a simulated model of how social primes influence the interpretation of the PRF that captures this aspect of the mechanism explicitly. Interpretation of the PRF differs in some ways from phoneme categorization because the mapping does not deal with how continuous phonetic variation relates to category selection. Instead, it involves only a single type of input which is mapped probabilistically onto one of two categories of illocutionary meaning. However, as the authors explain, predicting social priming effects in such a linguistic context is in fact a low-dimensional generalization of phoneme categorization. Using a limited number of simplifying assumptions concerning the influence of salient social cues on the baseline activation of their associated exemplars, the authors model how the social prime manipulation in their study is expected to influence the probability of interpreting the PRF as a question for individuals with different experience profiles. As Figure 4 shows, those profiles range from individuals who are only exposed to uses of the PRF by Corsican French speakers to individuals who are only exposed to uses by Continental French speakers. In other words, their model places native Corsican French speakers and native Continental French speakers on a single continuum. Darker shades, which correspond to a larger difference between the two social prime conditions in the selection of "question" interpretations of the
PRF, are concentrated near the center of the horizontal axis, reflecting the fact that individuals with more balanced experience are expected to show a more robust influence of the social prime manipulation.

The present study found no significant main effect of the social prime manipulation. Nevertheless the overall qualitative pattern was highly similar [2], suggesting that (perhaps some) Continental listeners may indeed have a low degree of sensitivity to the different social primes. The two sets of results can be related to the model simulation depicted in Figure 4 by comparing the differences in means for the CORSICAN versus CONTINENTAL conditions. For [2], this difference was 0.068 , while for the present study this difference was 0.037 . This detail suggests that the effect of the social prime manipulation differed only in magnitude across the two studies, and that the lack of significance in the present study was primarily due to the smaller size of the effect. Comparing with $[3,4]$, the discovery of a null finding is far from surprising, and does not, as [4] suggests, reflect a failure of social priming effects to generalize. Instead, the three studies together paint a picture that is precisely in line with the predictions of exemplar-based models: For populations that have more balanced exposure to two sociolectal patterns, contextual cues to social indices influence perception to a greater degree than for populations whose exposure to one sociolect is more limited.

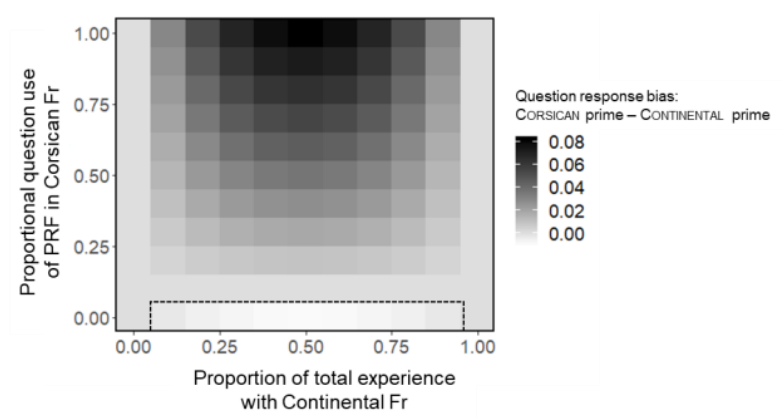

Figure 4: Predicted effect size of the prime manipulation (proportion of question responses in presence of CORSICAN prime minus proportion of question responses in presence of CONTINENTAL prime): on the $\mathrm{x}$-axis, the proportion of an individual's total experience that is associated with Continental French $(0=$ only Corsican French, $1=$ only Continental French); on the y axis, the proportion of all PRF uses by Corsican French speakers that are questions $(0=$ all PRF are used as statements, $1=$ all PRF are used as questions).

\section{Acknowledgements}

This work, carried out within the Labex BLRI (ANR-11LABX-0036) and the Institut Convergence ILCB

(ANR-16-CONV-0002), has benefited from support from the French government, managed by the French

National Agency for Research (ANR) and the Excellence Initiative of Aix-Marseille University (A*MIDEX). 


\section{References}

[1] Warren, P. (2017). The interpretation of prosodic variability in the context of accompanying sociophonetic cues. Laboratory Phonology: Journal of the Association for Laboratory Phonology, 8(1).

[2] Portes, C. \& German, J. S. (2019). Implicit effects of regional cues on the interpretation of intonation by Corsican French listeners. Laboratory Phonology: Journal of the Association for Laboratory Phonology 10(1): 22, pp. 1-26.

[3] Lawrence, D. (2015). Limited evidence for social priming in the perception of the bath and strut vowels. Proceedings of the 18th International Congress of Phonetic Sciences. Glasgow. UK: The University of Glasgow.

[4] Walker, M., Szakay, A., \& Cox, F. (2019). Can kiwis and koalas as cultural primes induce perceptual bias in Australian English speaking listeners?. Laboratory Phonology: Journal of the Association for Laboratory Phonology, 10(1).

[5] Johnson, K., Strand, E. A., \& D'Imperio, M. (1999). Auditoryvisual integration of talker gender in vowel perception. Journal of phonetics, 27(4), 359-384.

[6] Niedzielski, N. (1999). The effect of social information on the perception of sociolinguistic variables. Journal of language and social psychology, 18(1), 62-85.

[7] Hay, J., Warren, P., \& Drager, K. (2006b). Factors influencing speech perception in the context of a merger-in-progress. Journal of Phonetics, 34(4), 458-484.

[8] Hay, J., \& Drager, K. (2010). Stuffed toys and speech perception. Linguistics, 48(4), 865-892.

[9] Drager, K. (2011). Speaker age and vowel perception. Language and Speech, 54(1), 99-121.

[10] Johnson, K. (1997). Speech perception without speaker normalization: An exemplar model. In K. Johnson \& J. W. Mullennix (Eds.), Talker variability in speech processing (pp. 145-165).

[11] Johnson, K. (2007). Decisions and mechanisms in exemplarbased phonology. In M. Ohala \& M.-J. Solé (Eds.), Experimental approaches to phonology (pp. 25-40). Oxford: Oxford University Press.

[12] Boula de Mareüil, P., Rilliard, A., \& Maynard, H. (2016). Questions à intonation descendante: Un exemple d'isolat corse? In S. Retali-Medori (Ed.), Lingue delle isole, isole linguistiche (pp. 3-19). Alessandria: Edizioni dell'Orso.

[13] Post, B. (2000). Tonal and phrasal structures in French intonation. The Hague: Holland Academic graphics.

[14] Delais-Roussarie, E., Post, B., Avanzi, M., Buthke, C., Di Cristo, A., Feldhausen, I., \& Sichel-Bazin, R. (2015). Intonational phonology of French: Developing a ToBI system for French. In S. Frota \& P. Prieto (Eds.), Intonation in Romance (pp. 63-100). Oxford University Press.

[15] Portes, C., \& Beyssade, C. (2015). Is intonational meaning compositional. Verbum, 2.

[16] Sichel-Bazin, R. (2015). Prosodic systems in contact: Occitan and French. Doctoral dissertation, Universität Osnabrück Universitat Pompeu Fabra.

[17] Filippi, P. M. (1992). Le français régional de Corse. Étude linguistique et sociolinguistique. Unpublished doctoral dissertation, Corte, France: University of Corsica.

[18] Bates, D., Mächler, M., Bolker, B., \& Walker, S. (2014). Fitting linear mixed-effects models using lme4. arXiv preprint arXiv:1406.5823. DOI: https://doi.org/10.18637/jss.v067. i01

[19] R Core Team (2017): R: A language and environment for statistical computing. Vienna, Austria: $\mathrm{R}$ Foundation for Statistical Computing. http://www.R-project.org/. 